\title{
Predictors of intention to marriage based on theory of planned behavior among university students in Iran
}

Reza Shahrabadi ${ }^{1}$, Akram Karimi-Shahanjarini ${ }^{2}$, Saeed Dashti ${ }^{3}$, Alireza Soltanian ${ }^{4}$, Gholamreza Garmaroudi ${ }^{5}$

${ }^{1}$ Ph.D. Student in Health Education and Promotion, School of Public Health, Tehran University of Medical Sciences, Tehran, Iran

${ }^{2}$ Associate Professor, Social Determinants of Health Research Center and Department of Public Health, School of Public Health, Hamadan University of Medical Sciences, Hamadan, Iran

${ }^{3}$ Ph.D. Student in Health Education and Promotion, School of Public Health, Shahid Sadoughi University of Medical Sciences, Yazd, Iran

${ }^{4}$ Associate Professor, Modeling of Noncommunicable Diseases Research Center \& Department of Biostatistics, School of Public Health, Hamadan University of Medical Sciences, Hamadan, Iran

${ }^{5}$ Associate Professor, Department of Health Education and Promotion, School of Public Health, Tehran University of Medical Sciences, Tehran, Iran

\section{Type of article: Original}

\begin{abstract}
Introduction: Marriage is a social capital in society, so that makes the behavioral and social stability of parents and children in a generation, productive. Various factors can affect the intention of marriage, including individual, economic, social and cultural factors. The present study aimed to determine predictors of university students' intention to marriage based on the theory of planned behavior (TPB).

Methods: This cross-sectional study was performed among 192 single students (Master and PhD students with five to seven years of dentistry and medicine) in Hamadan, in 2014. The samples in this study were selected through convenient sampling. The data collection tools were demographic and TPB questionnaires. A questionnaire based on the TPB model was used in order to assess attitude toward behavior, subjective norms, perceived behavioral control, and intention. Data were analyzed by using SPSS16 and descriptive indexes, independent-samples t-test, One-way ANOVA and multivariate linear regression at 95\% significant level.

Results: The results showed that attitudes toward marriage $(\beta=0.217 ; p=0.001)$, subjective norms $(\beta=0.366$; $\mathrm{p}<0.001)$, and perceived behavioral control $(\beta=0.279 ; \mathrm{p}<0.001)$ significantly predicted students' intention to marriage. The TPB constructs explained $44 \%$ of the variance of intention.

Conclusion: Results indicated that strategies to improve the intention of marriage can include: expression of psychological needs such as having a companion, the importance of responsibility, society attitude of marriage, parents and marriage, the importance of the decision-making power and job position.

Keywords: Marriage, Students, Single person, Theory of planned behavior
\end{abstract}

\section{Introduction}

One of the major aspects of demographic research in recent years has been on issues of generational changes in the fields of marriage, fertility and family. In an era of rapid social and cultural changes, generational differences in attitudes lead to a gap between generations, and each generation will find a different philosophy and way of life (1). Marriage is a contract whereby, men and women live together in a united partnership and form a family (2). Delayed marriage can cause much damage in different aspects of life. The damage includes time of child-birth and damage caused by it, poor quality of partner and fading participation in society $(3,4)$ and also physical and mental poor health (5).Various factors delay the age of marriage such as economic factors, social norms, expectations of young

\section{Corresponding author:}

Associate Professor Dr. Akram Karimi-Shahanjarini, Social Determinants of Health Research Center and Department of Public Health, School of Public Health, Hamadan University of Medical Sciences, Hamadan, Iran. Tel: +98.8138380583, Email: karimi.a@umsha.ac.ir

Received: November 10, 2016, Accepted: March 13, 2017, Published: April 2017

iThenticate screening: February 14, 2017, English editing: March 19, 2017, , Quality control: April 02, 2017

(C) 2017 The Authors. This is an open access article under the terms of the Creative Commons Attribution-NonCommercialNoDerivs License, which permits use and distribution in any medium, provided the original work is properly cited, the use is non-commercial and no modifications or adaptations are made. 
people and education level $(6,7)$. Human societies during the last two centuries, have witnessed a significant increase in marriage age. The first increase took place in European countries, then, in the twentieth century proceeded to developing countries. A significant increase in the marriage age for girls, after years of experiencing early marriage, is a phenomenon in the field of social change $(8,9)$. Iran, like other developing countries, has experienced this phenomenon. According to the National Organization for Civil Registration of Iran, the average age of marriage for men and women from 1970 to 2010 increased from 25 to 26.4 years and from 18.5 to 23.5 years respectively (10). In Iran, the age of marriage among people who are studying in universities has increased (11). The average age of marriage among male and female students of the University of Medical Sciences is 29.1 and 27.2 years respectively, which shows the age of marriage in these students is 3 years longer than the average age of marriage in society (12). Because of the length of time in education, compared to other young people, students in the fields of Medical Sciences are faced with more obstacles and problems in their marriage and family formation $(8,9)$. Rezadoust's study (13) showed that Iranian girls with university education, marry later in life than other girls. The study showed that as education increases, delay in the marriage age increases, so that now, 78.5 percent of master students and above, have delay in the marriage age. Also, the Bahiraee study (14) revealed that 89.6 percent of MSc and $\mathrm{PhD}$ students have not intended to marry. In recent researches (11-14), education has been raised as one of the effective factors in the age of marriage and this study determines the reasons. Also, there are many theories for assessing the determinants of behavior (15). One of these theories is the theory of planned behavior (TPB) (16). In situations that assessment of behavior is difficult or impossible, TPB studies could be limited to assessing the intention to the given behavior (16). the theory of planned behavior can be useful in determining factors affecting the desire to get married (intention to marriage). the theory of planned behavior was introduced in 1985 and developed in 1991 by Ajzen and Fishbein. According to this theory, the most proximal determinant of behavior is individual intention to engage in a given behavior. In turn, intention is formed by attitudes, subjective norms, and perceived behavioral control. Attitude refers to a feeling or responding positively or negatively to something or someone. It is composed of beliefs and evaluations of behavioral outcomes. The subjective norm is defined as perceived social pressure that people feel to conduct a behavior. It is composed of normative belief and motivation to comply. The perceived behavioral control refers to people's beliefs about the ease or difficulty of the particular behavior. It is composed of control belief and perceived power (17). The theory of planned behavior predicts a wide range of health and non-health behaviors such as consumers' purchase intentions (18), healthy eating behaviors (19), physical activity (20) and oral health behaviors (21). Therefore, with regard to effects of university education in the age of marriage and that TPB can predict factors of such behavior (intention to marriage), this study aimed to investigate the determinants of university students' intention to marriage based on the TPB.

\section{Material and Methods}

\subsection{Research design and selection criteria}

This cross-sectional study was performed in October 2013 among 192 single students in Hamadan, a city in western Iran. The following inclusion criteria were considered: 1) Being master or $\mathrm{PhD}$ students and five to seven years of dentistry and medicine 2) Being single 3) Having written informed consent to participate in the study. Exclusion criterion was students who were divorced. The samples in this study were selected through convenient sampling (120 graduate students (Master and PhD), 31 dentistry students and 41 medical students).

\subsection{Instrument}

The demographic characteristics were obtained including age, gender, job, income, history of physical and mental illness, family financial status and number of family members. The TPB constructs was measured using a questionnaire including attitude toward marriage, subjective norms, perceived behavioral control, and behavioral intention. The questionnaires were designed by the researchers using review of related literature. Attitude was measured indirectly, based on behavioral beliefs and evaluations of behavioral outcomes by 18 items (e.g., If I marry I will have better social relationships with others) (Cronbach's alpha $=0.88$ ). Subjective norms were measured indirectly, using 11 items and based on motivation to comply and normative belief (e.g., what do you think about marriage of your single friends?) (Cronbach's alpha $=0.82$ ). Perceived behavioral control was assessed indirectly by 10 items (e.g., I am able to decide on marriage during education) and based on control belief and perceived power (Cronbach's alpha $=0.60)$. Behavioral intention was measured using 3 items (Cronbach's alpha $=0.69$ ). This questionnaire (Attitude, Subjective Norm and Perceived Behavioral Control) was designed based on a 5-point Likert scale (strongly disagree $=1$, disagree $=2$, neither agree nor disagree $=3$, agree $=4$, and strongly agree $=5$ ). Behavioral intention was a question with yes $(\mathrm{Score}=2)$ or no $(\mathrm{Score}=1)$ and two questions were designed based on a 5 -point Likert scale (not at all $=1$, slightly $=2$, moderately $=3$, very $=4$, extremely $=5$ ). The Content validity of the questionnaire was evaluated by a panel consisting of five experts. Questionnaires were completed with self-report. 


\subsection{Statistical analysis}

The data were analyzed using SPSS 16 (SPSS Inc., Chicago, Illinois, USA). Descriptive statistics, independentsamples t-test, one-way ANOVA and Multivariate Linear Regression were conducted to analyze data. The significance level was set at $\mathrm{p}<0.05$.

\subsection{Ethics of research}

The ethics committee of the Hamadan University of Medical Sciences approved the study protocol. Completing the questionnaire was voluntary and students were thoroughly assured about the confidentiality of the data. Informed consent was obtained from all the subjects.

\section{Results}

This study included 92 female and 98 male students, with the mean age of $25.57 \pm 2.99$ years old. Demographic status of students is presented in Table 1. Among participants, 116 students $(61.41 \%)$ had intended to get married. The results showed that the mean of TPB constructs was more than half of the obtainable scores (Table 2). Multivariate linear regression showed that attitude $(\beta=0.217 ; p=0.001)$, subjective norms $(\beta=0.366 ; p<0.001)$, and perceived behavioral control $(\beta=0.279 ; p<0.001)$ were the significant predictors of students' intention to marriage (Table 3). The TPB constructs explained $44 \%$ of the variance of students' intention to marriage.

Table 1. Demographic status of student (Their relation with intention to marriage) Criteria Demographic Variable

\begin{tabular}{|c|c|c|c|c|c|c|c|c|c|c|c|c|c|c|c|c|}
\hline & \multicolumn{4}{|c|}{ Birth order } & \multicolumn{2}{|c|}{$\begin{array}{l}\text { History of } \\
\text { mental illness }\end{array}$} & \multicolumn{2}{|c|}{$\begin{array}{l}\text { History of } \\
\text { physical illness }\end{array}$} & \multicolumn{3}{|c|}{$\begin{array}{l}\text { Family financial } \\
\text { status }\end{array}$} & \multicolumn{3}{|c|}{ Financial status } & \multicolumn{2}{|l|}{ Job } \\
\hline & $\geq 4^{\text {th }}$ & & $2^{\text {nd }}$ & $1^{\text {st }}$ & No & Yes & No & Yes & Good & Medium & Weak & Good & Medium & Weak & No & Yes \\
\hline an & 44 & 33 & 57 & 48 & 180 & 6 & 179 & 8 & 77 & 100 & 8 & 12 & 17 & 11 & 140 & 45 \\
\hline rcent & 24.2 & 18.1 & 31.3 & 26.4 & 96.8 & 3.2 & 95.8 & 4.2 & 41.6 & 54.1 & 4.3 & 33.3 & 40.5 & 26.2 & 57.7 & 24.2 \\
\hline value & 0.43 & & & & 0.48 & & 0.73 & & 0.30 & & & 0.63 & & & 0.12 & \\
\hline
\end{tabular}

Table 2. Mean, Standard deviation, and range of TPB constructs

\begin{tabular}{|l|l|l|l|l|l|l|}
\hline Variables & Mean & SD & Minimum & Maximum & Range & $\begin{array}{l}\text { Mean percentage of maximum } \\
\text { score }\end{array}$ \\
\hline Attitude & 4.09 & 0.52 & 2.61 & 5 & $1-5$ & 81.81 \\
\hline Subjective Norm & 3.38 & 0.70 & 1.45 & 5 & $1-5$ & 67.60 \\
\hline $\begin{array}{l}\text { Perceived Behavioral } \\
\text { Control }\end{array}$ & 3.16 & 0.62 & 1.30 & 5 & $1-5$ & 63.38 \\
\hline Behavioral Intention & 7.37 & 2.96 & 3 & 12 & $3-12$ & 61.41 \\
\hline
\end{tabular}

Table 3. Analysis of multivariate linear regression of theory of planned behavior for intention to marriage

\begin{tabular}{|l|l|l|l|l|l|l|l|l|}
\hline Variables & $\begin{array}{l}\text { Standardized } \\
\text { beta }\end{array}$ & $\begin{array}{l}\text { Unstandardized } \\
\text { beta }\end{array}$ & $\begin{array}{l}\mathrm{T} \\
\text { score }\end{array}$ & $\begin{array}{l}\mathrm{p}- \\
\text { value }\end{array}$ & $\mathrm{R}$ & $\mathrm{R}^{2}$ & $\begin{array}{l}\text { Adjusted } \\
\mathrm{R}^{2}\end{array}$ & $\begin{array}{l}\text { Change } \\
\text { in } \mathrm{R}^{2}\end{array}$ \\
\hline Attitude & 0.217 & 0.069 & 3.351 & $<0.001$ & 0.664 & 0.441 & 0.431 & 0.441 \\
\hline Subjective Norm & 0.366 & 0.144 & 5.082 & $<0.001$ & & & & \\
\cline { 1 - 5 } $\begin{array}{l}\text { Perceived Behavioral } \\
\text { Control }\end{array}$ & 0.279 & 0.132 & 4.265 & $<0.001$ & & & & \\
\hline
\end{tabular}

\section{Discussion}

This study was conducted to identify predictors of intention to marriage among students. In this study, there was no significant relationship between demographic variables with the intention to marriage. This finding is consistent with the results of Williams and French (22). Reasons of no significant relationship can be: 1) this study is measured by behavioral intention variable, not behavioral variable: to become the intention (marriage intention) to behavior (marriage) should be considered enabling factors such as money and facilities (23). So, it seems that demographic variables (that are concerned with enabling factors) are related with marriage (behavior). In this study, it was not possible to assess behavior. 2) This study was conducted on students who were in marriage age and older (with regard to cultural and social conditions) (9), and most of them (more than 50\%) were employed or were salaried by the university, so it seems that the role of economic factors is limited to form students' intention to marriage. Based on the findings, attitude was the significant predictor of intention. This result was similar to results of the study by 
Ajzen et al. (24) that was conducted on fertility intentions, and confirms the results of this study. In our study, in the case of this variable (Attitude), "Need to have a companion" and "Responsibility" were important to beliefs and evaluations of behavioral outcomes, respectively. Other studies also showed these results, for example, IbarraRovillard et al. (20) and Rodrigo-Gonzalez et al. (21) found that need to have a companion is a basic psychological need, for to take behavior and responsibility is an important factor to engage successfully in many behaviors. Therefore, the attitude toward behavior is an important factor to get married.. It seems that belief in having a companion and responsibility should be improved to encourage students to get married. Subjective norms were the significant predictor of intention, similar to findings by Collins et al. (27) about behavior of drinking. In this study" The acceptability of marriage in society morally" and "parents" were considered by students as normative belief and motivation to comply respectively. Farzadnia et al. (28), in their study, showed that acceptance of a behavior in society is an important factor to perform the behavior. Also, Hamdan et al. (29) found that parents can be the most influential to perform behavior and they are very important for youth's behavior. Therefore, based on our results, it can be concluded that the role of parents and acceptability of marriage in society is essential in marriage of students. In this study, perceived behavioral control was the significant predictor of students' intention to marriage. Lee et al. (30) revealed similar results about behavior of driving. In our study "be able during education" and "proper job" were found to control belief and perceived power, respectively. Gutnik et al. (31) showed that decision-making power is an important factor to perform a behavior and Seyfzadeh et al. (32) found that having a proper job is an important factor affecting the population intention of marriage. Thus, in this study, it was found that two important factors (due to perceived control structures), which include sense of empowerment and proper job, are effective on marriage of students. Limitations of this study were the questionnaire and its being self-reported and lack of cooperation by some of the students in completing the questionnaire.

\section{Conclusions}

Findings showed that there is significant relationship between attitudes, subjective norms and perceived behavioral control with behavioral intention (Intended to marry). The results indicated that strategies to improve the intention of marriage can include: expression of psychological needs such as having a companion, the importance of responsibility, society attitude of marriage, parents and marriage, the importance of the decision-making power and job position. It is recommended to use this model for intervention to marriage considering the variables mentioned above. These determinants can help in increasing marriage in students with mental approach (having a companion and decision-making power) and social approach (responsibility, society attitude, parents, job position).

\section{Acknowledgments:}

This research has ethical code by the local human subject review board of Hamadan University of Medical Sciences. Research reported in this publication was supported by the Vice Chancellor for Research and Technology, Hamadan University of Medical Sciences.

\section{Conflict of Interest:}

There is no conflict of interest to be declared.

Authors' contributions:

All authors contributed to this project and article equally. All authors read and approved the final manuscript.

\section{References:}

1) Steinmetz SK, Sussman MB, editors. Handbook of Marriage and the Family. Springer Science \& Business Media; 2013.

2) Jackson C. Introduction: Marriage, gender relations and social change. J Dev Stud. 2012; 48(1): 1-9. doi: 10.1080/00220388.2011.629653.

3) Palamuleni ME. Socioeconomic determinants of age at marriage in Malawi. Int J Sociol Anthropol. 2011; 3(7): 224-35.

4) Jones GW. Delayed marriage and very low fertility in Pacific Asia. Population and Development Review. 2007; 33(3): 453-78. doi: 10.1111/j.1728-4457.2007.00180.x.

5) Ola M, Mathur R. Is marriage essential for good physical and mental health of women? Indian Journal of Health and Wellbeing. 2016; 7(3): 359-62.

6) Peng TN. Trends in delayed and non-marriage in Peninsular Malaysia. Asian Population Studies. 2007; 3(3): 243-61. doi: 10.1080/17441730701746391. 
7) Miriam M. Determinants of delayed male marriage in Egypt. The stanford journal on muslim affairs. 2011; 2(1): 22-9.

8) Weir K, Pierce LM, Lucey C. Establishing Innovative Student Training Clinics for Counselor Educators and Marriage and Family Therapists. CLEARvoz Journal. 2014; 1(1): 19-34.

9) Heydari J, Jafary H, Afzali M, Mohamadpor R, Mahmodi G. Assessing unmarried students' marital criteria in mazandaran university of medical sciences in 2006. Iranian Journal of Nursing Research. 2008; 3(10): 53-60.

10) The National Organization for Civil Registration of Iran, Statistics and Information Office of Population and Migration. Analytical report of the event registration of marriage and divorce in the country with emphasis on national and international population indicators in 2010. 2016; 13-4.

11) Institute of Labour and Social Security. Comparison of marriage and divorce in iran 2010-2011. Journal of Work and Society. 2012; 148: 75-80.

12) Heydari J, Jafary H, Afzali M, Mohamadpor R, Mahmodi G. Criteria of marriage for single students of Mazandaran University of Medical Sciences. Iranian Journal of Nursing Research. 2008; 3(10): 56-62.

13) Rezadoust K, Mombeni I. The relationship of income, graduation and other variables with delay in marriage among single employed woman. Journal of applied counseling. 2011; 1(1): 105-22.

14) Hazrati $Z$, Bahiraee E. Social factors influencing age at marriage, female students (case study: working students in 1390 to study at Islamic Azad University, Science Research). Sociological studies of Iran. 2012; 2(4): 1-15.

15) Glanz K, Barbara K, Rimer K. Health Behavior And Health Education Theory, Research, and Practice. 4th ed. Jossey-Bass: 2008; 23-38.

16) Ajzen I. The theory of planned behavior. Organisational Behavior and Human Decision Processes. 1991; 50(2): 179-211. doi: 10.1016/0749-5978(91)90020-T.

17) Glanz K, Barbara K, Rimer K. Health Behavior And Health Education Theory, Research, and Practice. 4th ed. Jossey-Bass: 2008; 67-92.

18) Wang Y. Consumers' purchase intentions of shoes: theory of planned behavior and desired attributes. International Journal of Marketing Studies. 2014; 6(4): 50-8. doi: 10.5539/ijms.v6n4p50.

19) Fila SA, Smith C. Applying the theory of planned behavior to healthy eating behaviors in urban Native American youth. International Journal of Behavioral Nutrition and Physical Activity. 2006; 3(1): 1-10. doi: 10.1186/1479-5868-3-11.

20) Gholamnia Shirvani Z, Ghofranipour F, Gharakhanlou R, Kazemnejad A. Determinants of physical activity based on the theory of planned behavior in Iranian Military Staff's Wives: a path analysis. Global journal of health science. 2015; 7(3): 230-9. doi: 10.5539/gjhs.v7n3p230.

21) Dumitrescu AL, Wagle M, Dogaru BC, Manolescu B. Modeling the theory of planned behavior for intention to improve oral health behaviors: the impact of attitudes, knowledge, and current behavior. J Oral Sci. 2011; 53(3): 369-77. doi: 10.2334/josnusd.53.369. PMID: 21959666.

22) Williams SL, French DP. Theory of planned behaviour variables and objective walking behaviour do not show seasonal variation in a randomised controlled trial. BMC public health. 2014; 14(120): 1-10. doi: 10.1186/1471-2458-14-120.

23) Borhani M, Rastgarimehr B, Shafieyan Z, Mansourian M, Hoseini SM, Arzaghi SM, et al. Effects of predisposing, reinforcing and enabling factors on self-care behaviors of the patients with diabetes mellitus in the Minoodasht city, Iran. J Diabetes Metab Disord. 2015; 14(27): 1-6. doi: 10.1186/s40200-015-0139-0.

24) Ajzen L, klobas J. Fertility intentions: An approach based on the theory of planned behavior. Demographic Research. 2013; 29(8): 203-32.

25) Ibarra-Rovillard MS, Kuiper NA. Social support and social negativity findings in depression: perceived responsiveness to basic psychological needs. Clin Psychol Rev. 2011; 31(3): 342-52. doi: 10.1016/j.cpr.2011.01.005. PMID: 21382539.

26) Rodrigo-González A, Caballer-Tarazona M. A model to assess students' social responsibility behavior within a classroom experiment. Int Rev Econ Educ. 2015; 18: 62-82. doi: 10.1016/j.iree.2015.01.002.

27) Collins S, Witkiewitz K, Larimer M. The theory of planned behavior as a predictor of growth in risky college drinking. J Stud Alcohol Drugs. 2011; 72(2): 322-32. doi: 10.15288/jsad.2011.72.322. PMID: 21388605 , PMCID: PMC3052901.

28) Farzadnia S, Giles H. Patient-Provider Interaction: A Communication Accommodation Theory Perspective. IJSCL. 2015: 3(2): 17-34. 
29) Hamdan S, Mazariegos D, Melhem NM, Porta G, Payne MW, Brent DA. Effect of parental bereavement on health risk behaviors in youth: a 3 -year follow-up. Arch Pediatr Adolesc Med. 2012; 166(3): 216-23. doi: 10.1001/archpediatrics.2011.682. PMID: 22393180, PMCID: PMC3739453.

30) Lee C, Geiger-brown J, Beck K. Intentions and willingness to drive while drowsy among university students: An application of an extended theory of planned behavior model. Accid Anal Prev. 2016; 93: 113-23. doi: 10.1016/j.aap.2016.05.002. PMID: 27180286.

31) Gutnik LA, Hakimzada AF, Yoskowitz NA, Patel VL. The role of emotion in decision-making: A cognitive neuroeconomic approach towards understanding sexual risk behavior. J Biomed Inform. 2006; 39(6): 720 36. doi: 10.1016/j.jbi.2006.03.002. PMID: 16759915.

32) Seyfzadeh A, Ghanbari A. A Study on the Factors Affecting University Students' Attitudes on Marriage in Mahalat Payamnoor University. Sociol Stud Youth J. 2014; 5(15): 89-114. 